\title{
Türkiye'deki Kömür Madeni Kazalarına İlişkin Değerlendirme
}

\author{
Leyla DERIN ${ }^{1}$, Nehir VAROL ${ }^{1 *}$, Sadi UYMAZ ${ }^{1}$
}

Öz

Maden kazaları genellikle gelişmekte olan ülkelerin karşı karşıya kaldığı bir teknolojik afet olmakla birlikte küresel bir problemdir. Bu teknolojik afetler dünyanın her yerinde büyük oranda can kaybı, yaralanma ve ekonomik kayıplara sebep olmaktadır. İstatistikler Türkiye'de ve dünyada maden kazalarının büyük oranda kömür madenlerinde meydana geldiğini göstermektedir. 2010-2015 yılları arasında Türkiye'de ki maden kazalarının neden olduğu can kayıplarının \%81'i kömür madenlerinde meydana gelmiştir.

Türkiye'de kömür madenlerinde meydana gelen kazaların en yaygın sebepleri grizu patlaması, yangın, karbon monoksit zehirlenmesi, su baskını ve çökmelerdir. Sadece 2014 yılında, 301 madenci Soma-Eynez kömür madeninde yangın nedeniyle, 18 madenci ise Karaman-Ermenek kömür madeninde su baskını nedeniyle yaşamını yitirmiştir.

Maden kazalarının neden olduğu kayıpları önlemek/en aza indirmek için birincil adım risk azaltma çalışmalarıdır, bunun nedeni maden kazalarının genel olarak altyapı, teknoloji ve yönetim gibi önlenebilir sorunlarla ilişkili olmasıdır. Maden kazalarına yönelik başarıı bir risk azaltma planı, kazalara neden olan faktörlerin en iyi şekilde analiz edilmesini ve yorumlanmasını gerektirmektedir. Böyle bir yaklaşım, birçok maden kazasının önlenmesinde veya en az hasarla üstesinden gelinmesinde etkili olacaktır. Maden kazalarının önlenmesi ve kayıpların azaltılması için çeşitli risk azaltma çalışmaları yapılmıştır. Ancak, madencilik sektöründe işçi sağlığı ve iş güvenliği ile ilgili kanunlarda 2012 yılına kadar ciddi boşluklar bulunmaktadır. 2012 yılında yürürlüğe giren 6331 sayılı İ̧ Sağlığı ve Güvenliği Kanunuyla yönetmelikte önemli düzenlemeler yapılmıştır. Ayrıca, 2014 yılında da ilgili yönetmelikte bazı değişiklikler olmuştur. Ancak yaşanılan acı deneyimler, yapılan yeni düzenlemelerinde uygulanma ve izlenmesinin yetersiz kaldığını göstermektedir. Bu bakımdan, insan faktörünün yol açtığı maden kazalarına yönelik gerekli önlemlerin alınması ve izlenmesi madencilik faaliyetlerinin öncelikli görevi olmalıdır.

Bu çalışmada, Soma maden kazası örneği üzerinden Türkiye'de meydana gelen kömür madeni kazalarının değerlendirilmesi ile risk azaltma çalışmaları tartışııışır.

Anahtar Kelimeler : Risk azaltma, maden kazası, kömür madeni kazası, afet risk yönetimi

\section{Evaluation of the Coal Mines Accidents in Turkey}

\begin{abstract} accidents. inundation in the Karaman-Ermenek underground coal mine.

\footnotetext{
${ }^{1}$ Acil Durum ve Afet Yönetimi Bölümü, Ankara Üniversitesi, Beypazarı MYO

*ilgili yazar / Corresponding author: nehir.varol@ankara.edu.tr

Gönderim Tarihi: 7.12.2017

Kabul Tarihi: 30.12.2017
}

Mining accidents, considered as technological disasters, are global problems as well as usually common issues faced by developing countries. These accidents cause considerable number of deaths, injuries and economic losses worldwide. The statistics show that mining accidents occurred mostly in the coal mines in Turkey and also in the world. This is the fact that, in the period of 20102015 in Turkey, coal mining accidents caused approximately $81 \%$ of human casualties in the mining

Firedamp explosion, fire, carbon monoxide poisoning, inundation and collapsing of mine stopes are the most common causes of coal mining accidents in Turkey. Only in 2014, 301 miners died because of mine fire in the Soma-Eynez underground coal mine and 18 miners also died because of 
Türkiye'deki Kömür Madeni Kazalarına İlişkin Değerlendirme Evaluation of The Coal Mines Accidents in Turkey

In order to prevent/ mitigate deaths, injuries and economic losses caused by mining accidents, the primarily step is risk reduction studies because mining accidents are based on generally preventable issues like infrastructure, technology and management problems. A successful risk reduction plan for mining accidents requires analyzing and commenting the factors causing mining accidents in the best way. This risk approach will allow us to eliminate many mining accidents or overcome them with the least damage. Some risk reduction studies have conducted for prevention of mining accidents or reduction of the losses. Actually, there were serious gaps in the laws about occupational health and safety of workers in mining sector until 2012. The significant amendments were made to the regulations with the Act No. 6331 that came into force in 2012. Some amendments were also made to relevant regulations in 2014. However, the painful experiences show that the implementing and monitoring of existing regulations and amendments are insufficient. In that regard, taking and monitoring essential measures against work accidents caused by the human factor must be the primary task for mining activities.

In this study, risk reduction studies are discussed with evaluating of the coal mining accidents which occurred in Turkey.

Keywords: Risk reduction, mining accident, coal mining accidents, disaster risk management

\section{Giriş}

Madencilik faaliyetleri, insanlık tarihi boyunca önemini kaybetmeden var olmuştur (Xu vd., 2009). Nüfus artışı ve uygarlıkların gelişimi tarih öncesi zamanlardan günümüze kadar madenlere olan talebi sürekli arttırmıştır (Hartman ve Mutmansky, 2002). Gelişen teknoloji ile birlikte, madencilik sektöründe gelişmiş makine ve ekipmanların kullanımının iş kazalarını azaltması beklenmektedir. Diğer ekonomik sektörler arasında en tehlikeli sanayi sektörlerinden biri olan madencilik sektöründeki kazalar önemli ölçüde ölüm, yaralanma ve ekonomik kayıplara neden olmaktadır (Hermanus, 2007). 1902'den 2014'e kadar olan dönemde dünyadaki en büyük maden kazaları ve neden oldukları kayıplar Tablo 1'de özetlenmektedir. Tablo 1 'de de görüldüğü üzere sadece 26 maden kazasında yaklaşık 10.000 kişi yaşamını yitirmiştir. Dünyadaki ölümlü maden kazalarına ait verilere bakıldığında, özellikle kömür madeni kazalarının birçok ülkede meydana geldiği görülmektedir (Harris vd., 2014).

Tablo 1. 1900-2014 yılları arasında dünyada genelinde madenlerde meydana gelen büyük afetler.

\begin{tabular}{|c|c|c|c|}
\hline YII & Afet & Açıklama & Referans \\
\hline 1902 & $\begin{array}{l}\text { Kembla Dağı Kömür Madeni Felaketi New } \\
\text { South Wales, Illawarra, Avustralya }\end{array}$ & $\begin{array}{l}\text { Patlama nedeniyle } 96 \text { madenci } \\
\text { yaşamını yitirdi. }\end{array}$ & Dhillon, (2010) \\
\hline 1906 & $\begin{array}{l}\text { Courrieres Kömür Madeni Felaketi, } \\
\text { Fransa }\end{array}$ & $\begin{array}{l}\text { Patlama nedeniyle } 1099 \text { madenci } \\
\text { yaşamını yitirdi. }\end{array}$ & $\begin{array}{l}\text { www.mineacciden } \\
\text { ts.com.au }\end{array}$ \\
\hline 1907 & $\begin{array}{l}\text { Monongah Madeni Felaketi, Batı Virginia, } \\
\text { ABD }\end{array}$ & $\begin{array}{l}\text { Amerika tarihindeki en büyük } \\
\text { maden felaketi olan kazada } 362 \text { kişi } \\
\text { yaşamını yitirdi. }\end{array}$ & Dhillon, (2010) \\
\hline 1909 & $\begin{array}{l}\text { Cherry Kömür Madeni Felaketi, Illinois, } \\
\text { ABD }\end{array}$ & $\begin{array}{l}\text { Yangın nedeniyle } 259 \text { madenci } \\
\text { yaşamını yitirdi. }\end{array}$ & Dhillon, (2010) \\
\hline 1913 & $\begin{array}{l}\text { Senghenydd Kolleery Felaketi, Güney } \\
\text { Galler, Birleşik Krallık }\end{array}$ & 439 madenci yaşamını yitirdi. & Neville (1978) \\
\hline 1914 & $\begin{array}{l}\text { Hillcrest Kömür Madeni Felaketi, Hillcrest, } \\
\text { Alberta, Kanada }\end{array}$ & $\begin{array}{l}\text { Patlama nedeniyle } 189 \text { madenci } \\
\text { yaşamını yitirdi. }\end{array}$ & Dhillon, (2010) \\
\hline 1914 & $\begin{array}{l}\text { Mitsubishi Hojyo Kömür Madeni Felaketi, } \\
\text { Kyushu, Japonya }\end{array}$ & $\begin{array}{l}\text { Patlama nedeniyle } 687 \text { madenci } \\
\text { yaşamını yitirdi. }\end{array}$ & $\begin{array}{l}\text { www.mining- } \\
\text { technology.com }\end{array}$ \\
\hline 1921 & $\begin{array}{l}\text { Mount Mulligan Kömür Madeni Felaketi, } \\
\text { Queensland, Avustralya }\end{array}$ & $\begin{array}{l}\text { Patlama nedeniyle } 75 \text { madenci } \\
\text { yaşamını yitirdi. }\end{array}$ & Dhillon, (2010) \\
\hline 1942 & $\begin{array}{l}\text { Benxihu Colliery Kömür Madeni Felaketi, } \\
\text { Benxi, Liaoning, Çin. }\end{array}$ & $\begin{array}{l}\text { Dünyada ki en kötü maden } \\
\text { kazasında patlama sonucu } 1,549 \\
\text { madenci yaşamını yitirdi. }\end{array}$ & Dhillon, (2010) \\
\hline 1951 & $\begin{array}{l}\text { Batı Frankfort Kömür Madeni Felaketi, } \\
\text { Illinois, ABD }\end{array}$ & $\begin{array}{l}\text { Patlama nedeniyle } 119 \text { madenci } \\
\text { yaşamını yitirdi. }\end{array}$ & McAteer (1995) \\
\hline 1956 & $\begin{array}{l}\text { Bois du Cazier Felaketi, Marcinelle, } \\
\text { Belçika }\end{array}$ & 267 madenci yaşamını yitirdi. & $\begin{array}{l}\text { Vettel ve Herteln } \\
\text { (2010) }\end{array}$ \\
\hline
\end{tabular}


Reslilience (Dirençlilik) Dergisi Cilt: 1 Sayı: 1, 2017 (47-53)

Leyla DERIN, Nehir VAROL, Sadi UYMAZ

\begin{tabular}{|c|c|c|c|}
\hline 1958 & $\begin{array}{l}\text { Springhill Kömür Madeni Felaketi, } \\
\text { Springhill, Nova Scotia, Kanada }\end{array}$ & 74 madenci yaşamını yitirdi. & Dhillon, (2010) \\
\hline 1960 & $\begin{array}{l}\text { Coalbrook Kömür Madeni Felaketi, Güney } \\
\text { Afrika }\end{array}$ & $\begin{array}{l}\text { Göçük sonucu } 437 \text { madenci } \\
\text { yaşamını yitirdi. }\end{array}$ & Dhillon, (2010) \\
\hline 1960 & $\begin{array}{l}\text { Laobaidong Colliery Kömür Madeni } \\
\text { Felaketi, Datong, Shanxi, Çin }\end{array}$ & $\begin{array}{l}\text { Patlama nedeniyle } 684 \text { madenci } \\
\text { yaşamını yitirdi. }\end{array}$ & $\begin{array}{l}\text { www.mining- } \\
\text { technology.com }\end{array}$ \\
\hline 1963 & $\begin{array}{l}\text { Mitsui Miike Kömür Madeni Felaketi, } \\
\text { Mitsui Miike, Ōmuta, Fukuoka, Japan }\end{array}$ & 438 madenci yaşamını yitirdi. & $\begin{array}{l}\text { www.mineacciden } \\
\text { ts.com.au }\end{array}$ \\
\hline 1965 & $\begin{array}{l}\text { Dhanbad Kömür Madeni Felaketi, } \\
\text { Jharkhand, India }\end{array}$ & $\begin{array}{l}\text { Yangın sonucu } 375 \text { madenci } \\
\text { yaşamını yitirdi. }\end{array}$ & $\begin{array}{l}\text { www.mining- } \\
\text { technology.com }\end{array}$ \\
\hline 1966 & $\begin{array}{l}\text { Aberfan Felaketi, Aberfan, Merthyr Tydfil, } \\
\text { Galler }\end{array}$ & $\begin{array}{l}116 \text { çocuk, } 28 \text { yetişkin yaşamını } \\
\text { yitirdi. }\end{array}$ & $\begin{array}{l}\text { www.mineacciden } \\
\text { ts.com.au }\end{array}$ \\
\hline 1968 & $\begin{array}{l}\text { Farmington Madeni Felaketi. Batı Virginia, } \\
\text { ABD }\end{array}$ & $\begin{array}{l}\text { Patlama sonucu } 78 \text { madenci } \\
\text { yaşamını yitirdi. }\end{array}$ & $\begin{array}{l}\text { Saleh ve } \\
\text { Cummings (2011) }\end{array}$ \\
\hline 1972 & $\begin{array}{l}\text { Wankie Kömür Madeni Felaketi, Wankie, } \\
\text { Rhodesia, Zimbabwe }\end{array}$ & $\begin{array}{l}\text { Patlama nedeniyle } 427 \text { madenci } \\
\text { yaşamını yitirdi. }\end{array}$ & $\begin{array}{l}\text { www.mineacciden } \\
\text { ts.com.au }\end{array}$ \\
\hline 1975 & $\begin{array}{l}\text { Chasnala Kömür Madeni Felaketi, } \\
\text { Dhanbad, Jharkhand, India }\end{array}$ & $\begin{array}{l}\text { Patlama sonucu } 375 \text { madenci } \\
\text { yaşamını yitirdi. }\end{array}$ & $\begin{array}{l}\text { Singh ve Tripathi } \\
(2008)\end{array}$ \\
\hline 1986 & $\begin{array}{l}\text { Kinross Altın Madeni Felaketi, Güney } \\
\text { Afrika }\end{array}$ & 177 madenci yaşamını yitirdi. & Dhillon, (2010) \\
\hline 1993 & Nambija Madeni Felaketi, Ekvador & 300 madenci yaşamını yitirdi. & Pitta (2015) \\
\hline 1995 & $\begin{array}{l}\text { Vaal Reefs Altın Madeni Felaketi, Güney } \\
\text { Africa }\end{array}$ & 104 madenci yaşamını yitirdi. & $\begin{array}{l}\text { Wainwright } \\
\text { (2000). }\end{array}$ \\
\hline 2005 & $\begin{array}{l}\text { Sunjiawan Kömür Madeni Felaketi, Fuxin } \\
\text { Liaonning, Çin }\end{array}$ & $\begin{array}{l}\text { Patlama sonucu } 214 \text { madenci } \\
\text { yaşamını yitirdi. }\end{array}$ & Dhillon, (2010) \\
\hline 2007 & $\begin{array}{l}\text { Ulyanovskaya Kömür Madeni Felaketi, } \\
\text { Novokuznetsk, Kuzbass Sibirya, Rusya }\end{array}$ & $\begin{array}{l}\text { Patlama sonucu } 108 \text { madenci } \\
\text { yaşamını yitirdi. }\end{array}$ & Dhillon, (2010) \\
\hline 2014 & $\begin{array}{l}\text { Soma Kömür Madeni Felaketi, Soma, } \\
\text { Manisa, Türkiye }\end{array}$ & $\begin{array}{l}\text { Türkiye'nin ve 21. yüzyılın en büyük } \\
\text { maden kazasında } 301 \text { madenci } \\
\text { yaşamını yitirdi. }\end{array}$ & $\begin{array}{l}\text { Soma Maden } \\
\text { Faciası Raporu } \\
\text { (2014) (URL-1) }\end{array}$ \\
\hline
\end{tabular}

Türkiye'de meydana gelen ölümcül maden kazalarının sayısının son yıllarda giderek artmasıyla, madencilik sektöründe iş sağlığı ve güvenliği ile ilgili sistemdeki zayıf noktalar ve boşluklar tartışılmaya başlanmıştır. Türkiye Maden Mühendisleri Odası verilerine göre, 20102015 döneminde toplam 404 kömür madeni kazası meydana gelmiş olup bunların 232'si ölümcül kazalardır. Bu kazalarda 544 madenci yaşamını yitirirken, 374 madenci yaralanmıştır. Çalışma ve Sosyal Güvenlik Bakanlığı'nın İş Sağlığı ve Güvenliğine İlişkin İşyeri Tehlike Sınıfları Tebliği'ne göre madencilik faaliyetleri 'Çok Tehlikeli' kategorisinde yer almasına rağmen (URL-2), bu durum uygulamada yeterince dikkate alınmamaktadır.

\section{TÜRKIYE'DEKI KÖMÜR MADENI KAZALARI}

Uluslararası Çalışma Örgütü'ne (URL-3) göre, 2007-2012 arasında Türkiye'de üretilen bir milyon ton kömüre düşen maden kazalarındaki ölüm oranı dünyanın en büyük kömür üreticileri $A B D$ ve Hindistan ile kıyaslandığında oldukça yüksektir.

1983 ile 2015 yılları arası, kömür madenlerinde meydana gelen büyük kazalar nedeniyle Türkiye'deki yer altı kömür madenciliği için en ölümcül dönem olmuştur (Şekil 1). Bu dönemde, yaklaşık 19 madencilik felaketinde yaklaşık 1,000 madenci yaşamını yitirmiştir. Bu 19 kaza Tablo 2'de özetlenmiştir. 


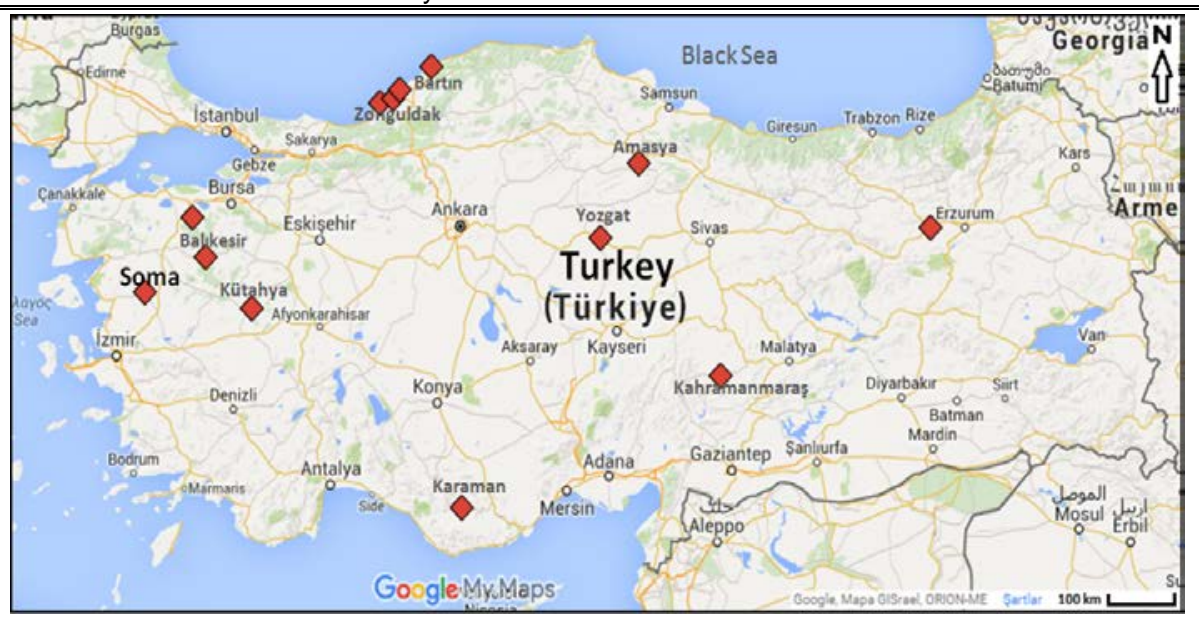

Şekil 1. Türkiye'de 1983 ve 2015 yılları arasındaki yer altı kömür madeni kazalarının lokasyonları

2014 yılında yaşanan maden kazaları ve bu kazaların neden olduğu can kayıpları Türkiye'de kömür madenlerindeki güvenlik sorunlarına işaret etmektedir(Tablo 2). 13 Mayıs 2014 tarihinde meydana gelen, 21. yüzyılın en kötü maden kazası olan Soma-Eynez kömür madeni faciasında, madende çıkan yangın nedeniyle 301 madenci yaşamını yitirirken, 122 madenci yaralanmıştır. 28 Ekim 2014 tarihinde meydana gelen Karaman-Ermenek kömür faciasında ise su baskını sonucu 18 madenci yaşamını yitirmiştir. 1992 yılında ZonguldakKozlu madeninde 263 madencinin hayatını kaybetmesiyle sonuçlanan maden kazası yaşanan en büyük maden kazasıyken, Soma faciası Türkiye Cumhuriyeti tarihi boyunca madencilik sektöründe yaşanan en büyük teknolojik afet olmuştur. Diğerleri gibi son iki büyük afet de çeşitli inmaller söz konusudur.

Tablo 2'de yer alan afetlerin nedenlerine bakıldığında, genellikle grizu patlaması, yangın, yangının sebep olduğu karbon monoksit zehirlenmesi, su baskını ve göçük büyük maden kazalarına neden olmuştur. Ayrıca, zehirli gaz sızıntısı, kömür tozu patlamaları, genel mekanik hatalar (madencilik ekipmanları ve makinalarının arızası veya hatalı kullanımı) vb. Türkiye'deki kömür madenlerinde çok fazla sayıda can kaybı ve yaralanmalara neden olmuştur. Kazaların meydana gelme sebeplerine bakıldığında çoğunun önlenebilir olduğu görülmektedir.

Tablo 2. 1983-2014 yılları arasında kömür madenlerinde afetler

\begin{tabular}{|c|l|c|l|}
\hline \multirow{2}{*}{ YıI } & Yer/Maden & Kayıp Sayısı & Neden \\
\hline 1983 & Zonguldak - Armutçuk & 103 & Grizu patlaması \\
\hline 1983 & Zonguldak - Kozlu & 10 & Grizu patlaması \\
\hline 1983 & Amasya-Yeniçeltek & 5 & Grizu patlaması \\
\hline 1987 & Zonguldak - Kozlu & 8 & Göçük \\
\hline 1990 & Bartın - Amasra & 5 & Grizu patlaması \\
\hline 1990 & Amasya-Yeniçeltek & 68 & Grizu patlaması \\
\hline 1992 & Zonguldak-Kozlu & 263 & Grizu patlaması \\
\hline 1995 & Yozgat-Sorgun & 37 & Grizu patlaması \\
\hline 2003 & Erzurum-Aşkale & 8 & Grizu patlaması \\
\hline 2003 & Karaman-Ermenek & 10 & Grizu patlaması \\
\hline 2005 & Kütahya-Gediz & 18 & Grizu patlaması \\
\hline 2006 & Balıkesir-Dursunbey & 17 & Grizu patlaması \\
\hline 2009 & Bursa-Mustafakemalpaşa & 19 & Grizu patlaması \\
\hline 2010 & Balıkesir-Dursunbey & 13 & Grizu patlaması \\
\hline 2010 & Zonguldak - Karadon & 30 & Grizu patlaması \\
\hline 2011 & Kahramanmaraş- Elbistan & 11 & Heyelan \\
\hline 2013 & Zonguldak - Kozlu & 8 & Grizu patlaması \\
\hline 2014 & Manisa- Soma (Eynez) & 301 & Yangın \\
\hline 2014 & Karaman-Ermenek & 18 & Su baskını \\
\hline Tablodaki veriler, Türk Mühendis ve Mimar Odaları Birliği'nin, Soma Maden Faciası TMMOB Raporu (2014) (URL-4)'ndan derlenmiştir.
\end{tabular}




\section{TARTIŞMA}

Dünyada, madencilik sektöründe kömür madenlerinde yaşanan kazalarda önemli miktarda can kayıplarının meydana gelmesi, bu sektörde detaylı bir düzenleme yapılması ve iş sağlı̆̆ı ve güvenliği önlemlerinin alınmasını gerektirmektedir. Türkiye de kömür madenlerinde meydana gelen kazalar; can kaybı, yaralanma ve ekonomik kayıplar yönüyle Dünya ile kıyaslandığında, Türkiye de bu kayıpların daha ziyade sistemsel zayıfıklar ve boşluklar nedeniyle yaşandığı dikkat çekmektedir.

Soma-Eynez Kömür madeninde 301 madencinin yaşamını yitirmesine neden olan felakete ilişkin Soma Maden Kazası Bilirkişi Raporu'na (2014) (URL-5) göre kaza çeşitli inmaller nedeniyle yaşanmıştır. Some-Eynez maden kömürünün 150 C0'ye ulaştığında kendiliğinden yanarak yangın çıkarabilecek özellikte olması, grizu patlamasına veya gizli yangına sebep olabileceğini göstermektedir (Yılmaz, 2002). Bilirkişi raporuna göre, kömürün ısınması sonucu oluşan yüksek miktarda CO maden içerisinde yüksek sıcaklıkta hava akışına neden olmuştur. Maden içerisinde yüksek orandaki CO miktarı gaz izleme sensörlerine ait kayıtlarda yer almasına karşın herhangi bir önlem alınmamıştır. Rapora göre, Soma felaketine olan çeşitli inmaller mevcuttur. Bunlardan bazıları; artan üretim miktarı ve madenci sayısına uygun olmayan havalandırma sistemi ve yöntemi, kolay yanabilir malzeme ve teçhizatın kullanılması, yetersiz CO maskeleri ve iletişim ekipmanları, güvenilir olmayan elektrik sistemi, düzensiz gaz ölçüm kayıtları, yetersiz ve arızalı gaz ve sıcaklık sensörleri ve tehlikeli üretim yöntemidir. Bunlar, teknik olarak önlenebilir risklerdir. Bununla birlikte bilirkişi raporu sonuçlarına göre, mevcut yönetmeliğin uygulanmaması Soma-Eynez maden felaketinin en önemli nedenlerinden biri olmuştur. Soma-Eynez madeninde, 6331 sayılı İş Sağlığı ve Güvenliği Kanunu'na (2012) göre zorunlu olan acil durum tahliye planlaması olmamakla birlikte, acil çıkış galerisi de mevcut değildir. Bununla birlikte ilgili yönetmelikte yeraltı madenleri yangınlarına ilişkin uygulanması gereken risk değerlendirme ve risk azaltma yöntemlerine ilişkin yeterli bilgi ve yaptırım olmaması bu felakete neden olan etmenlerden biri olmuştur.

Yukarıda ifade edilen nedenlere ek olarak, ISG uzmanlarının sayısı ve iş sağlığı ve güvenliği eğitimleri yetersizdir. Bu eğitimler özellikle Soma-Eynez madeni için kritik önem taşımaktadır. Bunun nedeni, madende çalışan birçok madencinin geçimlerini madende çalışmadan önce tarım ve hayvancılık alanlarından sağlamasıdır (URL-6).

Benzer sebeplerden ötürü başka madencilik kazaları da yaşanmıştır. Küçük veya büyük maden kazalarına neden olma potansiyeline sahip bu tehlike unsurlarının toplamı SomaEynez kazası gibi büyük çaplı bir afetin yaşanmasına neden olmuştur. 


\section{SONUÇLAR}

1983-2015 yılları arasındaki teknolojik gelişmeler ve Türkiye'deki önleme-kontrol ve risk azaltma ile ilgili yasa ve kanunlar incelendiğ inde kömür madenciliği sektöründeki felaketlerin azalması beklenmektedir. Ancak, 2014 yılı Türkiye'de yeraltı kömür madenciliği için en ölümcül yıl olmuştur. Bu durum, kömür madenciliği sektöründe iş güvenliği uygulamalarındaki inmallerin, en kritik sorun olduğuna işaret etmektedir.

Teknolojik ve yönetim sorunları gibi önlenebilir sebeplerden kaynaklanan maden kazalarının neden olduğu can kaybı, yaralanma ve ekonomik kayıpları önlemek için risk azaltma çalışmalarına özel dikkat gösterilmelidir. Maden kazalarına yönelik başarılı bir risk azaltma planlaması, bu kazalara neden olan koşul ve unsurların en iyi şekilde analiz edilmesini ve yorumlanmasını gerektirmektedir. Böyle bir risk odaklı yaklaşım, birçok maden kazasının önlenmesini sağlayacaktır.

Kömür madenciliği faaliyetlerinin doğası gereği tehlikeli olması, olası bir felaketin yaşanmaması için gerekli tüm tedbirlerin alınmasını zaruri kılmaktadır. Geçmişte yaşanan acı deneyimler, düşük olasılığın dahi bu sektörde oldukça büyük kayıplara neden olabileceğini göstermiştir. 2012 yılına kadar madencilik sektörüne yönelik iş sağlığı ve güvenliği yasalarında önemli boşluklar bulunmaktadır. Ancak, 2012 yılında yürürlüğe giren 6331 sayılı İş Sağlığı ve Güvenliği Kanunu (URL-7) ile birlikte yönetmelikte önemli düzenlemeler yapılmıştır. Ayrıca, 6552 sayılı Kanunla (URL-8); 4857 sayılı İş Kanunu'nunda (URL-9) ve 6331 sayılı İş Sağlığı ve Güvenliği Kanunu'nda bazı değişiklikler yapılmıştır. Bu değişiklerin bazıları yeraltı çalışanlarının çalışma koşulları ve taşeronların yükümlülükleri içermektedir.

Madencilik sektöründe yaşanılan deneyimler maden facialarının önlenmesine ilişkin yasa ve yönetmeliklerin mevcut olmasına rağmen, bunların uygulanma ve izlenmesinin yetersiz olduğunu göstermektedir. İnsan faktörünün yol açtığı iş kazalarına karşı gerekli önlemlerin alınması madencilik faaliyetlerinin öncelikli görevi olmalıdır. 


\section{KAYNAKLAR}

1. Dhillon, B. S. (2010). Global mine accidents. Mine Safety: A Modern Approach, 59-71.

2. Harris, J., Kirsch, P., Shi, M., Li, J., Gagrani, A., Anand Krishna, E. S., ...\& Cliff, D. (2014). Comparative Analysis of Coal Fatalities in Australia, South Africa, India, China and USA. Naj Aziz, 399.

3. Hartman, H. L., \& Mutmansky, J. M. (2002). Introductory Mining Engineering. John Wiley \& Sons.

4. Hermanus, M. A. (2007). Occupational health and safety in mining-status, new developments, and concerns. Journal of the South African Institute of Mining and Metallurgy. 107(8), 531-538.

5. McAteer, J. D. (1995). The Federal Mine Safety and Health Act of 1977: Preserving a Law that Works. W. Va. L. Rev., 98, 1105.

6. Neville, R. G. (1978). The courrieres colliery disaster, 1906. Journal of Contemporary History, 13(1), 33-52.

7. Pitta, T. (2015). Catastrophe: A Guide to World's Worst Industrial Disasters. Vij Books India Pvt Ltd.

8. Saleh, J. H., \& Cummings, A. M. (2011). Safety in the mining industry and the unfinished legacy of mining accidents: safety levers and defense-in-depth for addressing mining hazards. Safety science, 49(6), 764-777.

9. Singh, R. S., \& Tripathi, N. (2008). Indian coal Mine Disasters and their Management. Jharkhand Journal of Development and Management studies, 6(2), 2865-2879.

10. Vettel, P., \& Hertel, G. (2010). Current status of fire-resistant hydraulic fluids meeting European underground mining standards. Journal of ASTM International, 8(1), 1-7.

11. Wainwright, K. A. (2000). Risk assessment of hoisting with and without a safety detaching hook.

12. Xu, L., Song, H., \& Jin, W. (2009, June). Optimizing the Structures of Reclaimed Land Use in Coal Mining Area. In 2009 3rd International Conference on Bioinformatics and Biomedical Engineering (pp. 1-4). IEEE.

13. Yılmaz, A. İ. (2002). Eynez Yeraltı Ocağı havalandırma sisteminin ocak yangınlarına etkisi. Dokuz Eylül Üniversitesi, Fen Bilimleri Enstitüsü, Doktora Tezi. İzmir.

14. URL-1: Soma Maden Faciası Raporu, http://www.barobirlik.org.tr/dosyalar/duyurular/20141112_somamadenfaciasipdf.pdf (Son Erişim: 20.10.2017)

15. URL-2: ILO. (2016). Türkiye'de Kömür Madenciliği Sektöründe Sözleşmesel Düzenlemeler. http://www.ilo.org/wcmsp5/groups/public/---europe/---ro-geneva/---iloankara/documents/publication/wcms_458151.pdf (Son Erişim: 20.10.2017)

16. URL-3: Resmi Gazete (28509 sayılı) (2012). http://www.resmigazete.gov.tr/eskiler/2012/12/20121226-11.htm (Son Erişim: 20.10.2017)

17. URL-4: Soma Maden Faciası TMMOB Raporu, (2014). http://www.tmmob.org.tr/fles/ somaraporu.pdf (Son Erişim: 20.10.2017)

18. URL-5: Soma Maden Kazası Bilirkişi Raporu, (2014).

19. URL-6: Boğaziçi Üniversitesi Soma Araştırma Grubu Raporu. (2015). Soma Ziyareti Saha Gözlem Raporu. (Son Erişim: 20.10.2017) http://www.busomarastirmagrubu.boun.edu.tr/sites/default/fles/calismaraporu.pdf

20. URL-7: Resmi Gazete (28339 sayılı). http://www.resmigazete.gov.tr/eskiler/2012/06/20120630-1.htm (Son Erişim: 20.10.2017)

21. URL-8: Resmi Gazete (29116 sayılı). http://www.resmigazete.gov.tr/eskiler/2014/09/20140911M1-1.htm (Son Erişim: 20.10.2017)

22. URL-9.

$$
\text { Resmi Gazete (25134 sayılı). }
$$
http://www.resmigazete.gov.tr/eskiler/2003/06/20030610.htm (Son Erişim: 20.10.2017) 